\title{
Managing the Cumulative Impacts of Land Uses in the Western Canadian Sedimentary Basin: A Modeling Approach
}

\author{
$\underline{\text { Richard, R. Schneider }}^{1}, \underline{\text { J. Brad Stelfox }}^{2}, \underline{\text { Stan Boutin }}^{3}$, and $\underline{\text { Shawn Wasel }}^{4}$
}

\begin{abstract}
This case study from northeastern Alberta, Canada, demonstrates a fundamentally different approach to forest management in which stakeholders balance conservation and economic objectives by weighing current management options from the point of view of their long-term effects on the forest. ALCES ${ }^{\circ}$, a landscape-scale simulation model, is used to quantify the effects of the current regulatory framework and typical industrial practices on a suite of ecological and economic indicators over the next $100 \mathrm{yr}$. These simulations suggest that, if current practices continue, the combined activities of the energy and forestry industries in our $59,000 \mathrm{~km}^{2}$ study area will cause the density of edge of human origin to increase from $1.8 \mathrm{~km} / \mathrm{km}^{2}$ to a maximum of $8.0 \mathrm{~km} / \mathrm{km}^{2}$. We also predict that older age classes of merchantable forest stands will be largely eliminated from the landscape, habitat availability for woodland caribou will decline from 43 to $6 \%$, and there will be a progressive shortfall in the supply of softwood timber beginning in approximately $60 \mathrm{yr}$. Additional simulations involving a suite of "best practices" demonstrate that substantial improvements in ecological outcome measures could be achieved through alternative management scenarios while still maintaining a sustainable flow of economic benefits. We discuss the merits of our proposed approach to land use planning and apply it to the Western Canadian Sedimentary Basin.
\end{abstract}

\section{INTRODUCTION}

The petroleum deposits in the Western Canadian Sedimentary Basin (Fig. 1) represent one of the world's largest hydrocarbon resources (Petroleum Communication Foundation 2000:4). The development of this resource began in the 1950s and proceeded rapidly, particularly during the 1990s. Forests within the Western Canadian Sedimentary Basin (WCSB) are also subject to commercial forestry operations that have likewise expanded in recent decades. In addition, the Peace River region of Alberta and British Columbia supports a large agricultural industry.

The combined effects of the energy, forestry, and agriculture industries are threatening the integrity of the forests of the WCSB; integrity in this case is defined as the degree to which all ecosystem components and their interactions are represented and functioning. The forest land base is shrinking, human access is steadily increasing, and forest stands are changing in composition and becoming younger and more fragmented (Alberta Environmental Protection $1998 a$ ). The root of the problem is the current system of management, which lacks meaningful ecological objectives and fails to integrate the overlapping activities of resource companies.

Fig. 1. Extent of the Western Canadian Sedimentary Basin (blue) and the location of our study area (red).

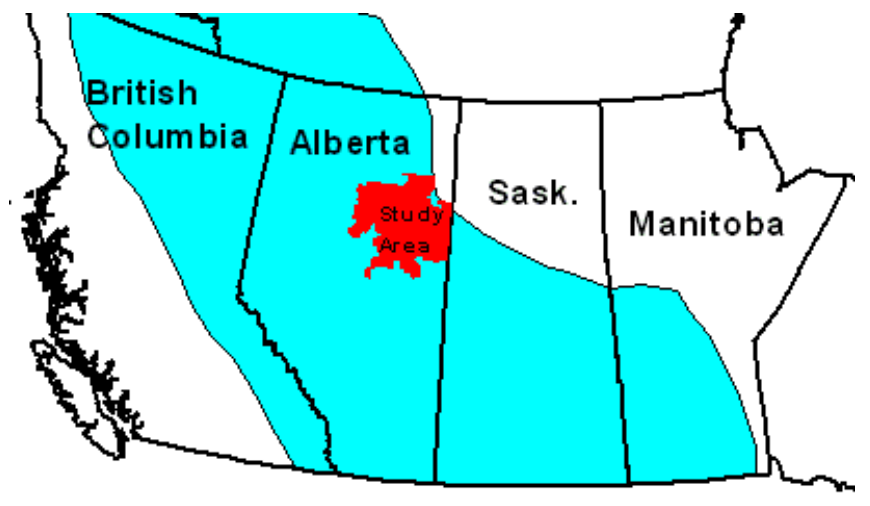

In this paper we present a case study that demonstrates a fundamentally different approach to forest management. In this approach, stakeholders weigh current management options from the point of view of 
their long-term effects on the forest in an attempt to balance conservation and economic objectives. In our case study, we use ALCES ${ }^{\circ}$, a landscape-scale simulation model, to quantify the effects of the current regulatory framework and typical industrial practices on a suite of ecological and economic indicators over the next $100 \mathrm{yr}$. We also use the model to explore an alternative management scenario involving the application of several "best practices" that are currently being advocated.

\section{INTEGRATED RESOURCE MANAGEMENT IN ALBERTA}

Of the various provinces and territories included in the Western Canadian Sedimentary Basin (WCSB), industrial development occurred first and has made the most progress in Alberta (Wetherell and Kmet 2000). Hence, Alberta serves as a microcosm for development patterns that can be expected throughout the WCSB.

Although integrated resource management was first attempted in Alberta back in the 1970s, different industrial sectors continue to be managed by different government agencies using different policy instruments (Kennett 2002). Environmental protection is still handled through piecemeal regulations focused on mitigating the local short-term effects of specific industrial activities. Strategies for achieving long-term ecological objectives at the regional scale, including limits on cumulative industrial effects, have yet to be implemented (Kennett 2002). For example, despite a surfeit of regulations governing the conduct of seismic exploration, there is no limit on the cumulative density of lines.

In the absence of an integrative planning framework, resource companies generally plan their activities independently, even if they operate on the same land base. For example, the planning and construction of road networks by petroleum companies and forestry companies are usually carried out independently and without reference to cumulative road densities, in spite of the obvious cost savings and reduced environmental effects that could be achieved with a combined network.

Because there is nothing within the current regulatory framework to prevent further increases in the cumulative industrial footprint, there is a risk that populations of sensitive forest species will decline and that the province's general goal of maintaining forest integrity will not be achieved. For example, species such as woodland caribou (Rangifer tarandus caribou) and walleye (Stizostedion vitreum) have been shown to be adversely affected by linear disturbances and increased human access (Dyer et al. 2001, Post and Sullivan 2002). The loss of old-growth stands is having a negative impact on other species, including many forest birds (Benkman 1993, Kirk et al. 1996). There is also concern that the progressive loss of timber from petroleum industry activities and fire, which were not taken into account when forestry tenures were allocated, may threaten the viability of some forestry companies in future decades.

\section{METHODS}

\section{Study area}

The study area was the Forest Management Agreement Area of Alberta-Pacific Forest Industries Inc. (Al-Pac), which encompasses $59,054 \mathrm{~km}^{2}$ in northeastern Alberta, Canada (Fig. 1). Except for a few scattered hill systems, the area has minimal topographic relief. Pure and mixed stands of aspen (Populus) and white spruce (Picea glauca) are the most common species in upland sites, although jack pine (Pinus banksiana) predominates on drier sites (Alberta Environmental Protection 1994a). Lowland sites are characterized by open stands of black spruce (Picea mariana) and tamarack (Larix laricina) and by extensive peatland complexes (Alberta Environmental Protection 1994a). The study area contains $23,842 \mathrm{~km}^{2}$ of potentially merchantable forest as well as extensive oil and gas deposits. The oil deposits include conventional liquid oil, heavy (low viscosity) oil, and oil sands (a mixture of semisolid oil and sand). Industrial activity within the study area was minimal in the first half of the 20th century (Wetherell and Kmet 2000) but expanded rapidly thereafter. The forest industry, including Al$\mathrm{Pac}$ and several smaller companies, currently clears a total of $16,000 \mathrm{ha} / \mathrm{yr}$ on the study area, compared with $11,000 \mathrm{ha} / \mathrm{yr}$ for the petroleum sector. Because certain features of the petroleum industry, e.g., seismic lines, wellsites, and pipelines, persist on the landscape, they have a greater cumulative impact than do forest industry features that, by regulation, must be quickly regenerated to forest. We used GIS map overlays provided by Al-Pac to quantify the industrial footprint of the study area in 2002 (Table 1). Included in the industrial footprint were all areas of the forest land base currently in a nonforest state as a result of industrial activity. We did not include forestry 
cutblocks in the tally because they are immediately regenerated to forest; however, in-block haul roads and landings, which experience delayed regeneration, were included. These data were used to define the initial state of the forest for the ALCES model runs.

Table 1. Amount of the forest land base in a nonforest state in 2002 affected by industrial disturbance.

\begin{tabular}{lc}
\hline Type of disturbance & Area (ha) \\
\hline Seismic lines & 41,082 \\
Pipelines & 22,258 \\
Roads (minor) & 20,000 \\
Pasture grass & 19,992 \\
Wellsites & 15,516 \\
Roads (major ) & 11,606 \\
Roads (wellsite) & 7346 \\
Oil- sand surface mine & 155,162 \\
Recreation areas & 5829 \\
Miscellaneous agriculture & 3100 \\
\hline
\end{tabular}

\section{The ALCES model}

ALCES (A Landscape Cumulative Effects Simulator) was developed over a period of $7 \mathrm{yr}$ for the purpose of tracking industrial footprints and ecological processes under alternative management scenarios; for more information, please see www.foremtech.com/index.htm. To facilitate scenario analysis, ALCES provides results within minutes, even for very large landscapes such as our $59,000 \mathrm{~km}^{2}$ study area. ALCES is, in essence, a bookkeeping model that depends largely on user input to describe the processes being simulated. The user must specify the initial state of the landscape and provide quantitative assumptions concerning future industrial activities, natural disturbances, and regeneration trajectories for each disturbance type. On the basis of the information provided, the model tracks and updates the state of the landscape in 1-yr time steps for as long as requested. When only forest harvesting and regeneration are activated, the model is functionally equivalent to the aspatial timber supply models used by forestry companies for long-term harvest planning (Forestry Corporation 2002). The major advantage of ALCES is that the user can include a variety of additional disturbances of natural and human origin in model runs. The suite of available ecological output measures is also far greater than what is typically included in timber supply models. When simulating large landscapes rapidly using current computer hardware, it is not possible to track the spatial location of all the landscape features. Instead, ALCES permits users to stratify the landscape into multiple subunits that are tracked independently. For example, the forest land base can be stratified into several stand types, and different harvest and regeneration strategies can be applied to each stratum. For some types of industrial activity, new disturbances may overlap existing features. For example, new seismic programs are sometimes conducted along existing seismic lines that have not yet regenerated. To account for spatial overlap in ALCES, the user must specify the average proportion of new disturbances that overlap existing features. Changing the proportion of overlap of features between model runs may be an important component of a scenario comparison, as it was in this study. For the most part, ALCES allows industrial activities and natural disturbances to occur either deterministically or stochastically.

\section{Modeling assumptions}

For the analysis presented here we limited the disturbance types to forest harvesting, petroleum exploration and development, road construction, and fire. Although ALCES can also track the activities of the agricultural and mining sectors, these were of 
minor significance in our study area and were not included in the study. Forest harvesting protocols were matched to conventional practices in use in Alberta. The basic approach in Alberta is a two-pass clearcut system with a 70-yr rotation for hardwoods and a 100$\mathrm{yr}$ rotation for softwoods. We also matched silvicultural systems and stand growth and yield curves to current industry norms. Further details concerning current forestry practices in Alberta are provided in the provincial Operating Ground Rules (Alberta Environmental Protection 1994b). To model the future trajectory of petroleum industry activities, we assumed that drilling would continue at the current rate (Fig. 2) until reserves were depleted (Fig. 3). Because only $1 \%$ of the $50 \times 10^{9} \mathrm{~m}^{3}$ of potentially recoverable oil-sands reserves have been recovered to date, these reserves will last well into the next century (Alberta Energy and Utilities Board 2001:2). We used separate trajectories for conventional oil, gas, and oil sands in the model (Fig. 4). Data on historical trends in the rate of seismic line development were incomplete for the study area. However, from Al-Pac's GIS dataset we determined that an average of $3 \mathrm{~km}$ of seismic lines is generated for each well drilled, and this relationship was used in the model runs. Similarly, we used a ratio of $0.1 \mathrm{~km}$ of pipeline for each well drilled. Other petroleum sector variables were changed as part of the scenario comparison described below. Based on AlPac's road development plan, together with anticipated road construction associated with energy sector development, we estimated that $75 \mathrm{~km} / \mathrm{yr}$ of permanent roads would be built over the next $50 \mathrm{yr}$. At that point, the permanent road network in the study area will be relatively complete. We also estimated that an average of $500 \mathrm{~km}$ of temporary access roads would be required each year for the next $50 \mathrm{yr}$; after that, the construction of temporary roads would gradually taper off. Permanent and temporary roads represent long-term deletions from the forest land base. Since 1980, fire has burned an average of $0.65 \%$ of northern Alberta per year, excluding water bodies, and the rate appears to be rising (Alberta Sustainable Resource Development 2002). Estimates of long-term rates of fire, based on mathematical analysis of forest age structure and fire history data, range from $0.4 \% / \mathrm{yr}$ (Cumming 1997) to 2.2\%/yr (Murphy 1985). Balancing these various sources of information, we selected a fire rate of $1 \% / \mathrm{yr}$ for the model runs. Instead of varying the area burned stochastically, we used a constant fire rate to simplify comparisons between alternative management scenarios. Fire salvage logging was not included in the model.
Fig. 2. Cumulative number of wells in the study area and Alberta, 1970-1999. Superimposed are the cumulative number of wells in the first $30 \mathrm{yr}$ of the model run. Data are expressed as the annual percent increase relative to year 0 , to facilitate direct comparison.

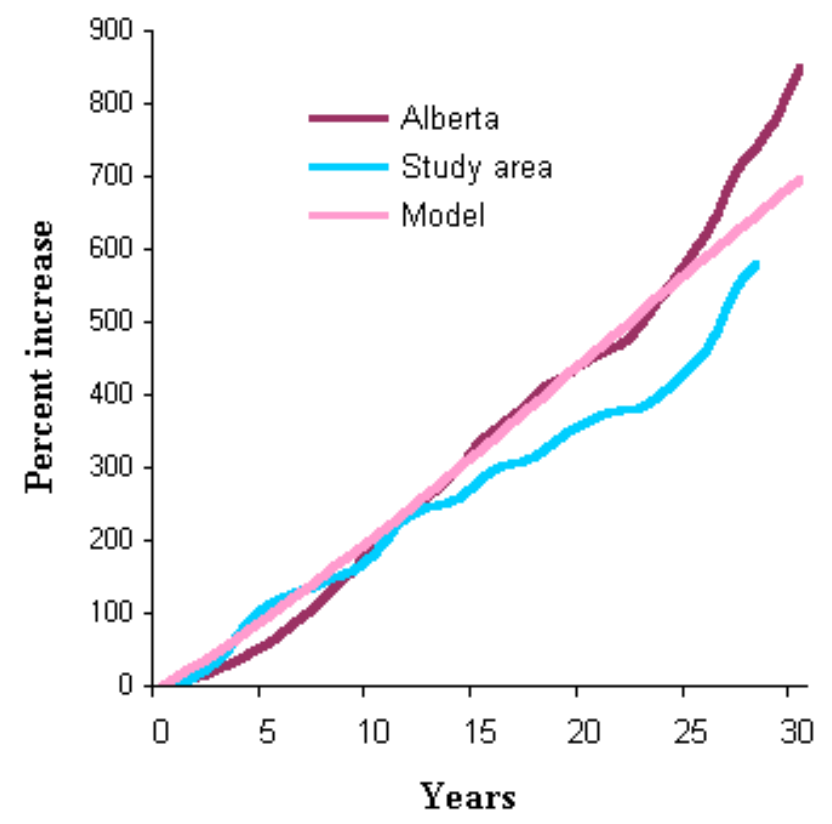

Fig. 3. Conventional oil and gas reserves in Alberta, 19562000 (Alberta Energy and Utilites Board 2001).

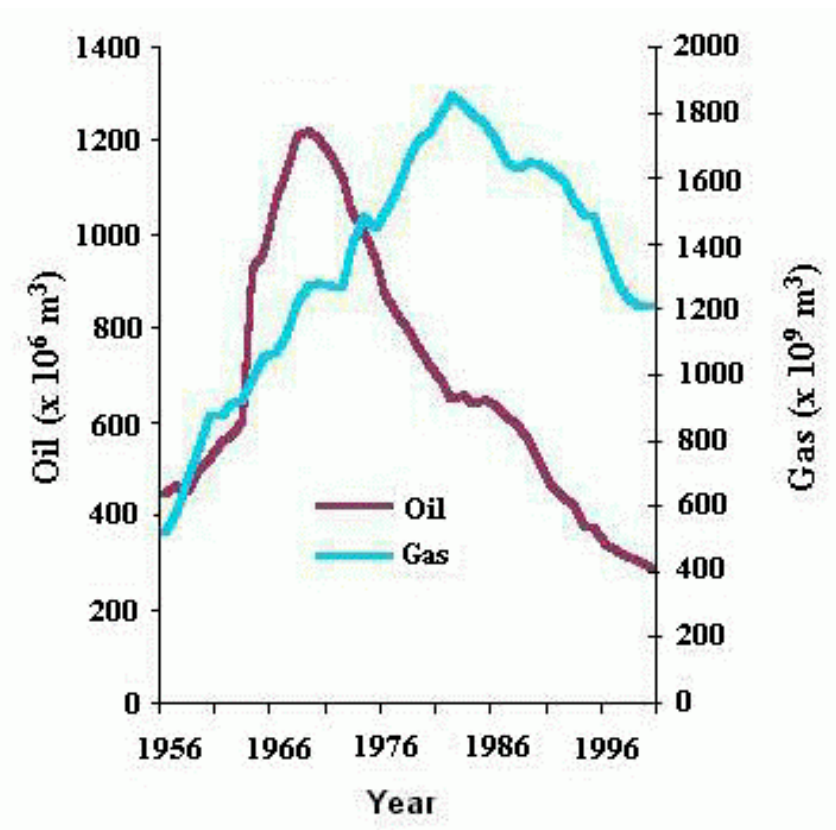


Fig. 4. Annual number of new wells used in all model runs, by product type.

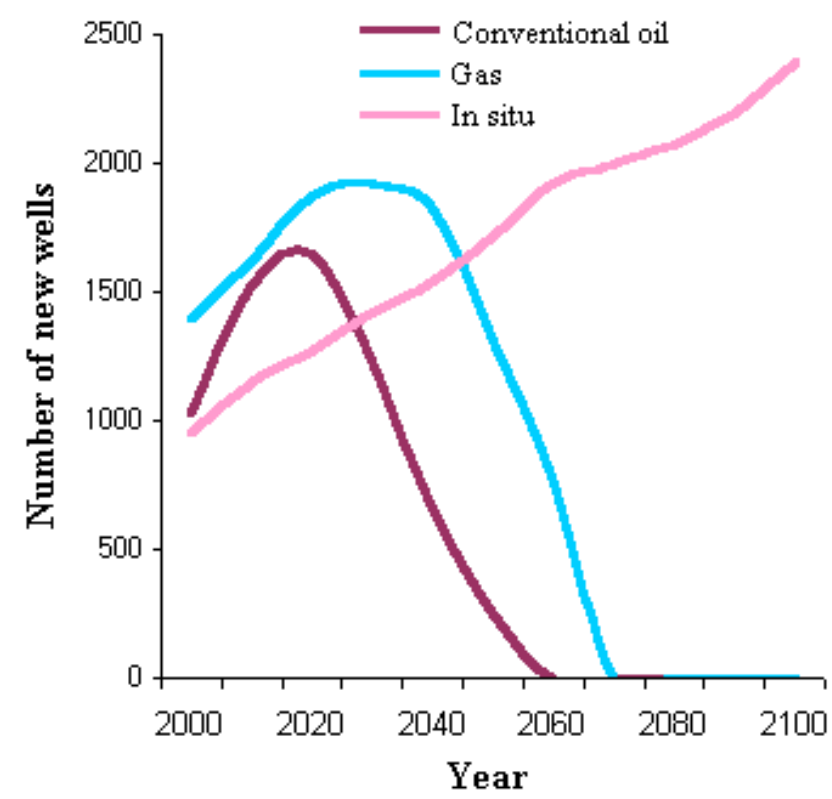

Fig. 5. Density of human-origin edge expressed as $\mathrm{km}$ of edge $/ \mathrm{km}^{2}$. BAU stands for "business as usual," BP for "best practices."

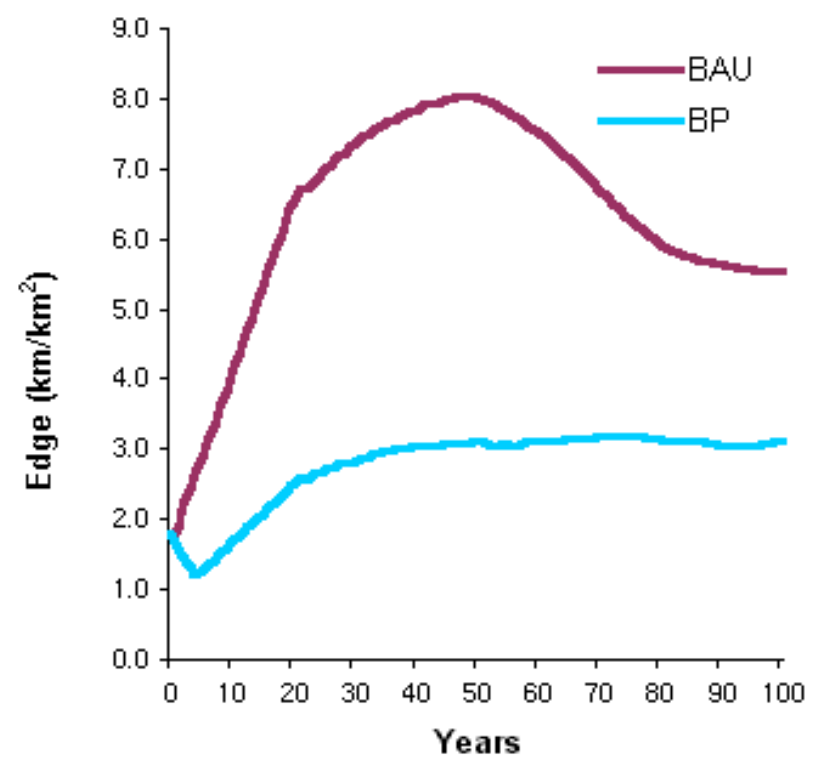

\section{Scenario analysis}

To demonstrate the utility of the model, we investigated two management scenarios. The first was a representation of conventional practices, which we termed "business as usual" (BAU). The other scenario, termed "best practices" (BP), was a modified management strategy intended to be more ecologically and economically sustainable. The list of elements used to define best practices was not comprehensive. Our intent was simply to demonstrate the gains that could be expected from a few basic measures that could realistically be implemented without major technological impediments. For the forestry sector, best practices included a change in harvesting protocols that would exclude a proportion of older stands from harvest (Table 2). There was also an increase in variability in cutblock size and a reduction of in-block losses, e.g., by establishing haul roads and $\log$ storage areas within the cutblock. For the petroleum sector, a series of changes was implemented to decrease the magnitude of the annual footprint, assuming a fixed rate of development; these changes included increased road harmonization with the forestry sector (Table 2). Best practices for the energy sector also included measures to promote the reclamation of disturbed areas.

ALCES is able to report on a broad suite of ecological and economic indicators in addition to basic output measures such as harvest volume and forest age-class structure. For purposes of illustration, we selected habitat availability for caribou as an additional ecological indicator for this study. The parameter estimates for caribou habitat availability used in the model represent the consensus estimate of 20 biologists with caribou experience and were determined through a workshop process. The key parameter affecting the scenario analysis is the avoidance distance of caribou from human disturbances, which ranges from $100 \mathrm{~m}$ for seismic lines to $500 \mathrm{~m}$ for roads. These data largely reflect the findings of Dyer et al. (2001), who quantified caribou avoidance of industrial features using radiotelemetry.

\section{RESULTS}

Under the business-as-usual (BAU) scenario, the industrial footprint within the study area increased dramatically over the $100-\mathrm{yr}$ simulation period. The clearest measure of this footprint is the density of human-origin edge, which increased from $1.8 \mathrm{~km} / \mathrm{km}^{2}$ to a maximum of $8.0 \mathrm{~km} / \mathrm{km}^{2}$ (Fig. 5). Under the best practices (BP) scenario, the maximum density of human-origin edge was $3.2 \mathrm{~km} / \mathrm{km}^{2}$. 
Table 2. Model assumptions used in the scenario analysis.

\begin{tabular}{|c|c|c|}
\hline Variable & Business as usual & Best practice \\
\hline Harvest of hardwoods & $\begin{array}{l}\text { Oldest first, minimum harvest } \\
\text { age }=70 \text { years }\end{array}$ & $\begin{array}{c}\text { No harvest of stands }>120 \text { years, minimum } \\
\text { harvest age }=70 \text { years }\end{array}$ \\
\hline Harvest of softwoods & $\begin{array}{l}\text { Oldest first, minimum harvest } \\
\text { age }=100 \text { years }\end{array}$ & $\begin{array}{c}\text { No harvest of stands }>140 \text { years, minimum } \\
\text { harvest age }=100 \text { years }\end{array}$ \\
\hline Cutblock size & $\begin{array}{l}\text { All cutblocks }=21-40 \text { ha in } \\
\text { size }\end{array}$ & $\begin{array}{c}\text { Cutblock size distribution: } \\
\text { - } 1-2120 \% \\
\text { - } 21-40 \mathrm{ha}=45 \% \\
\text { - } 41-80 \mathrm{ha}=25 \% \\
\text { - } 81-160 \mathrm{ha}=10 \%\end{array}$ \\
\hline $\begin{array}{l}\text { In-block losses (haul roads, } \\
\text { landings) }\end{array}$ & $5 \%$ & $2 \%$ \\
\hline $\begin{array}{l}\text { Road harmonization between the } \\
\text { petroleum sector and forestry } \\
\text { sector }\end{array}$ & $10 \%$ sharing of new roads & $50 \%$ sharing of new roads \\
\hline Width of seismic lines & $5 \mathrm{~m}$ & $1 \mathrm{~m}$ \\
\hline Reforestation of seismic lines & 25 year lag (seeded to grass) & 4 year lag \\
\hline $\begin{array}{l}\text { Spatial overlap of new seismic } \\
\text { lines with existing linear } \\
\text { disturbances }\end{array}$ & $10 \%$ & $50 \%$ \\
\hline $\begin{array}{l}\text { Spatial overlap of new pipelines } \\
\text { lines with existing linear } \\
\text { disturbances }\end{array}$ & $10 \%$ & $50 \%$ \\
\hline Number of wells per drill pad & 1 & 2 \\
\hline $\begin{array}{l}\text { Reforestation of well sites after } \\
\text { decommissioning }\end{array}$ & 25 year lag (seeded to grass) & Immediate replanting of trees \\
\hline
\end{tabular}

Ecological attributes also experienced a major change in the BAU run. Old-growth stands of softwoods (> $140 \mathrm{yr}$ ) were eliminated within $20 \mathrm{yr}$, and old-growth stands of hardwoods (> $100 \mathrm{yr}$ ) in $65 \mathrm{yr}$ (Figs. 6A and 6B). Available caribou habitat declined rapidly from 43 to $6 \%$ of the land base (Fig. 7). Under the BP run, the amount of old-growth forest declined as well, but the rate of decline was not as rapid, particularly for softwoods (Figs. 6A and 6B). Although there was also a decline in the availability of caribou habitat in the $\mathrm{BP}$ run, at least half of the original amount remained at all times (Fig. 7). In the BAU scenario, a shortfall in the availability of harvestable softwood timber was observed relative to the approved annual allowable cut in approximately $60 \mathrm{yr}$ (Fig. 8). A similar pattern was observed in the BP run, although the onset of the shortfall was delayed by about a decade. A shortfall in the hardwood harvest did not occur in either scenario. 
The model also demonstrated that existing practices carry a substantial economic cost. Petroleum companies must pay a prescribed fee to forestry companies for wood that they remove as part of their operations. These timber damage fees averaged Can. $\$ 1.316 \times 10^{6} / \mathrm{yr}$ in the BAU run, compared with Can. $\$ 521,000$ in the BP run. The difference in biotic carbon storage between the two runs amounted to 5.8 $\mathrm{Mg} / \mathrm{ha}$. At a rate of Can. $\$ 10 / \mathrm{Mg}$ for carbon credits, this amounts to Can. $\$ 342 \times 10^{6}$ over the study area.

\section{DISCUSSION}

Until about 1950, our study area could be characterized as boreal wilderness (Wetherell and Kmet 2000). By 2000 it had undergone a profound transformation as a consequence of accelerating industrial development (Alberta Environmental Protection 1998a). However, this transformation pales in comparison to the changes that, based on our predictions, will occur in coming decades unless the current regulatory framework and operating practices are modified.

According to our model, there will be a progressive reduction in the forest land base, the remaining forest will become progressively younger and more fragmented, and there will be a marked increase in human access. The cumulative industrial footprint, in terms of density of linear disturbance and total area disturbed, will quadruple over the next 20-30 yr, and then level off.

Because these predictions are for the most part based on a simple projection of current trends, they are relatively robust. Indeed, localized examples of development at the high intensities predicted by the model already exist in Alberta in areas where industry is mature (Alberta Environmental Protection 1998a). Moreover, more than Can. $\$ 50 \times 10^{9}$ in new petroleum developments in northern Alberta have already been announced (Alberta Resource Development 2001:15). In cases where accurate estimates of model parameters were unavailable, we intentionally chose conservative estimates so that our results could not be construed as a worst-case scenario.

The increase in the density of human-origin edge is primarily attributable to industrial features that persist on the landscape, leading to cumulative impacts far in excess of the annual rate of disturbance. Most prominent among these features are seismic lines, because they are generated at a high rate and require decades to regenerate under current practices (Revel 1984, Osko and MacFarlane 2001). Roads, wellsites, pipelines, and in-block losses associated with harvesting are also important contributors to humanorigin edge.

Fig. 6. Graph A represents the proportion of the land base in old-growth softwood, graph B the proportion of the land base in old-growth hardwood. BAU stands for "business as usual," BP for "best practices."

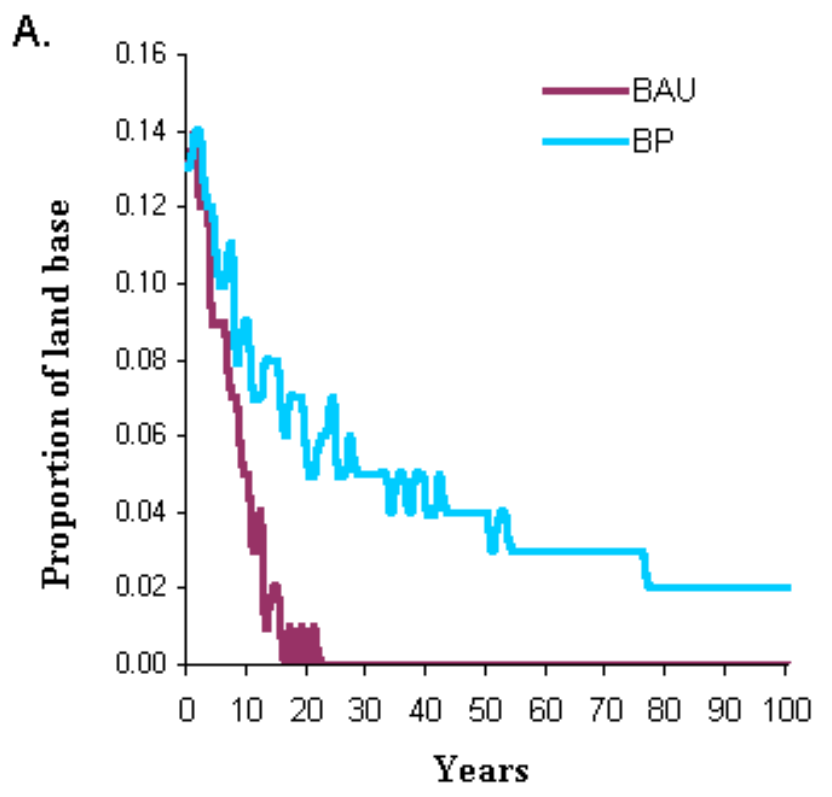

B.

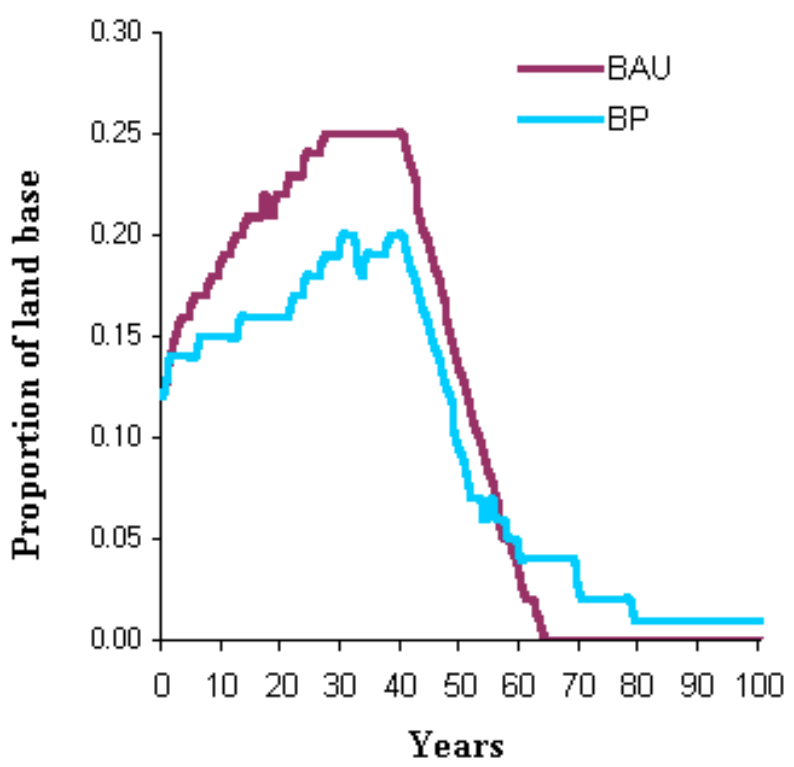


Fig. 7. Availability of caribou habitat. BAU stands for "business as usual," BP for "best practices."

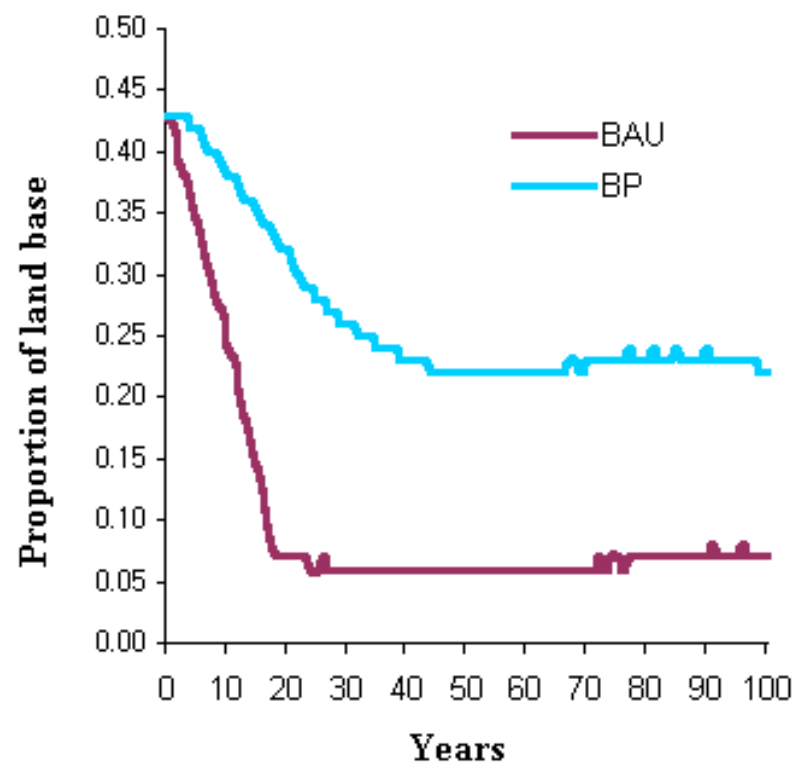

Fig. 8. Annual harvest volume of softwoods. BAU stands for "business as usual," BP for "best practices."

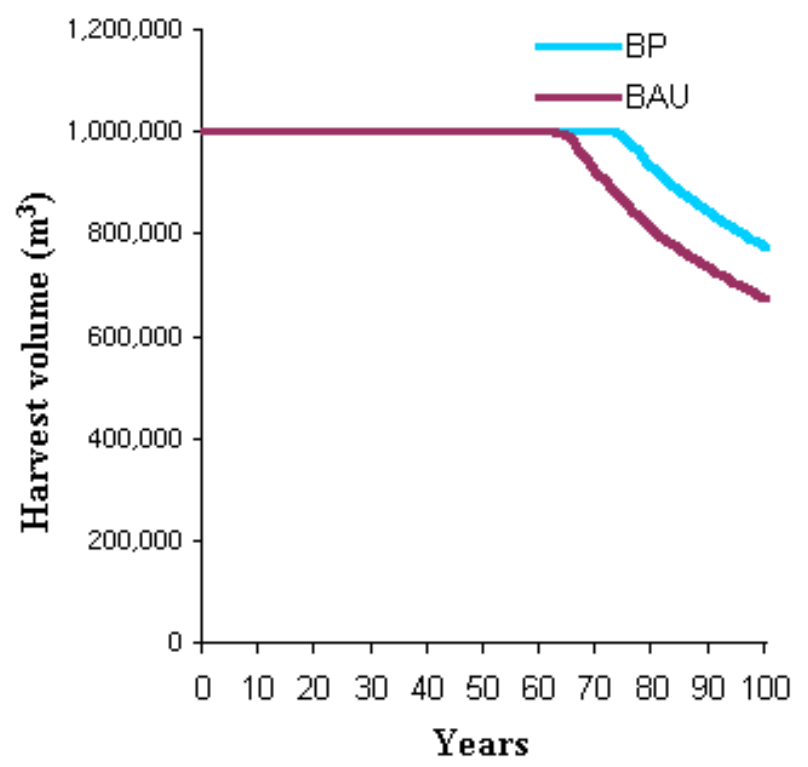

Our finding that the industrial footprint will expand most rapidly over the next two decades and then decline is somewhat counterintuitive, given that conventional oil and gas reserves are already in a state of decline in Alberta (Alberta Energy and Utilities Board 2001). However, the annual rate of production in the near term is limited mainly by economic factors and industry capacity, not the size of the reserves. The policy of the provincial government is focused on maximizing short-term economic returns from the remaining reserves, and the royalty system has been structured to ensure that this occurs (Macnab et al. 1999). Petroleum companies share the desire to develop rapidly because there is a risk that alternative forms of energy may reduce the future demand for petroleum and because oil that is extracted provides cash for investment, whereas oil in the ground does not. In consequence, the conventional oil and gas sector is poised to undergo a pronounced "boom and bust" cycle over the next 20-30 yr, which will end when the reserves are depleted. The exception to this pattern is the development of the oil-sands deposits, which are sufficiently large to last well into the next century (Alberta Energy and Utilities Board 2001).

Another structural change to the forest predicted by our model is the elimination of old-growth, beginning with softwood, stands. This result is the direct manifestation of current forestry practices in which the oldest stands are logged first (Alberta Environmental Protection 1994b). Although forest clearing by the petroleum industry and fire do not target older stands specifically, they do remove some old growth by chance and thus increase the rate at which old-growth forest is lost.

The changes in the forest structure predicted by the model are expected to have a significant effect on forest wildlife. Species dependent on old-growth and interior habitats are likely to decline as their preferred habitat types are lost from the landscape (Benkman 1993, Donovan et al. 1995, Kirk et al. 1996). Species that are sensitive to human disturbance, such as woodland caribou, are also likely to experience a decline. In our model, the availability of caribou habitat decreased from $43 \%$ of the study area to $6 \%$ as a consequence of industrial development. Because caribou are already listed as threatened in Alberta (Dzus 2001), this magnitude of effective habitat loss is a serious cause for concern. The great increase in road infrastructure is also likely to result in problems. In addition to the loss and fragmentation of habitat, roads cause soil erosion, disruption of water and fish movements, changes in animal movement patterns, and increased access by humans, which leads to more hunting and poaching (Jones et al. 2000, Trombulak and Frissell 2000). 
In addition to the aforementioned ecological effects, the current system of forest management will have negative socioeconomic repercussions. Foremost among these is a shortfall in the supply of softwood timber in approximately $60 \mathrm{yr}$. Because mills have substantial fixed costs, running below full capacity translates into reduced economic return and in some cases may result in mill closure. This timber shortfall will occur because annual harvest rates are currently based on the rate of tree growth, without accounting for losses from fire and the activities of the petroleum sector (Alberta Environmental Protection 1996). Salvage logging cannot fully compensate for these external losses because more than half of the merchantable forest lost to fire and the petroleum sector is too young, too damaged, or too inaccessible to be used (Alberta-Pacific Forest Industries Inc., unpublished data). Moreover, as time passes and the forest becomes progressively younger, less wood lost to external causes is suitable for salvage, and all sources of disturbance effectively become additive.

There are economic repercussions for the petroleum industry as well. The fees that petroleum companies must pay to forestry companies for timber damage will amount to tens of millions of dollars in coming decades. This is a lose-lose situation in that the economic loss to the petroleum industry does nothing to restore the forest in the areas that are disturbed. The current system also ignores potential credits that could be gained by petroleum companies for maintaining carbon stores on the landscape. According to our simulation, these credits could amount to hundreds of millions of dollars for the petroleum industry if best practices were implemented. Finally, the current system foregoes substantial cost savings that would accrue if the petroleum industry and forest industry were to harmonize their road networks.

The underlying reason for the various problems illustrated by our modeling exercise is that the current system of forest management in Alberta is a relic of earlier times. The present system is essentially unchanged from the 1950s, when it was established to maximize economic returns from resource extraction in the north. Since then, two important changes have occurred. First, the once pristine forest is now so densely occupied by industrial operators that interference among companies and sectors is commonplace. Second, as a consequence of shifting public values, there now exist ecological objectives (e.g., Alberta Forest Conservation Strategy Steering Committee 1997) that cannot be adequately addressed by the current system of management.

What is required, to start, is an acceptance that the days of the open frontier are over. The attitude that the forest can be all things to all interests is no longer tenable, if indeed it ever was. Although the boreal forest presents a seemingly endless expanse, it does in fact have limits, and they are now being reached. Consequently, future management of the forest will occur in the context of tradeoffs among competing interests and objectives.

Finding the appropriate balance among competing objectives requires three features that are lacking in the current system of forest management: meaningful stakeholder involvement, integrated planning, and an assessment of how current management decisions will affect the forest of the future. Given the complexity of forest management issues, a decision support system of some form should be considered a necessity.

Computer models designed to address specific forest management issues are already available, e.g., timber supply and habitat supply models, so it is remarkable that decision support systems have not previously been applied to the management of the forest as a whole. The scenario analysis we present here is intended to demonstrate the utility and feasibility of such a global system. Through our modeling exercise, the cumulative landscape-level effects of small localized disturbances became clearly apparent. We were able to demonstrate that the current system of forest management in Alberta is unlikely to achieve the government's stated ecological objectives (Alberta Environmental Protection 1998b) and is also deficient with respect to economic objectives. Furthermore, we were able to demonstrate that a few basic changes in management protocol, primarily involving integration among sectors, reduction in the impact of petroleum industry activities, and retention of old-growth forest, would have a major beneficial effect on ecological outcomes.

Even though our collection of best practices did not represent a comprehensive list of possible changes, they did produce major improvements in several ecological outcome measures relative to current practices. Best practices were of particular value in minimizing fragmentation and human access and in maintaining caribou habitat. Our findings suggest that additional measures will be required to maintain oldgrowth forest, e.g., floating old-growth reserves, although our set of best practices did have some 
benefit. Finally, although the best practices did not alleviate the shortfall in softwood timber supply, they did not worsen it either. On the other side of the equation, the best practices were associated with significant economic benefits to the petroleum industry from reduced timber damage fees, reduced road construction costs, and credits for carbon storage. It is important to note that our suite of best practices did not include any reduction in the production of hydrocarbons.

In practice, we expect that the greatest utility of our modeling approach will be in facilitating land use planning among groups of stakeholders. The primary benefit of the model is that it provides a level playing field for stakeholders to assess the costs and benefits associated with alternative management options. The effects of individual activities from different sectors are made apparent, which should help stakeholders to understand how these activities interact and accumulate and how the limitations of a finite system constrain management options. Because stakeholders must make explicit their assumptions and objectives and work together to define scenarios and assess their output, the model also facilitates communication. The active engagement of stakeholders in the modeling process and the transparency of the model, in which the key processes are all under the control of the user, promotes the understanding and acceptance of the outcomes.

Despite the strengths of our modeling approach, there are several limitations to its use. First, because users are effectively in full control of the model, they must understand the system they are working in if they are to set the parameters of the model and interpret the results in a meaningful way. Furthermore, the collection of the required data can be time-consuming and expensive. Finally, the model does not predict the future, it simply demonstrates the logical outcomes of the trends described by the user. Consequently, it should be used within an adaptive management framework in which management regimes are considered hypotheses to be tested, rather than fixed outcomes (Walters and Holling 1990). Within this context, our modeling approach should lead to improved decision making by helping stakeholders balance objectives and avoid management approaches with a very high likelihood of failure. We expect this approach to be particularly useful in less developed regions of the Western Canadian Sedimentary Basin, because the range of management options in those areas would be less constrained by existing industry than it is in Alberta.
Responses to this article can be read online at: http://www.consecol.org/vol7/issl/art8/responses/index.html

\section{Acknowledgments:}

We thank the other members of the Adaptive Management Experiment Team for their input on this manuscript. Funding for this study was provided by Alberta-Pacific Forest Industries Inc.

\section{LITERATURE CITED}

Alberta Energy and Utilities Board. 2001. Alberta's reserves 2000 and supply/demand outlook 2001-2010. Statistical Series 2001-98. Alberta Energy and Utilities Board, Calgary, Alberta, Canada.

Alberta Environmental Protection. 1994a. Alberta timber harvest planning and ground rules. Alberta Environmental Protection, Edmonton, Alberta, Canada.

Alberta Environmental Protection. 1994b. Natural regions of Alberta. Alberta Environmental Protection, Edmonton, Alberta, Canada.

Alberta Environmental Protection. 1996. The status of Alberta's timber supply. Alberta Environmental Protection, Edmonton, Alberta, Canada.

Alberta Environmental Protection. 1998a. The boreal forest natural region of Alberta. Alberta Environmental Protection, Edmonton, Alberta, Canada.

Alberta Environmental Protection. 1998b. The Alberta forest legacy. Alberta Environmental Protection, Edmonton, Alberta, Canada.

Alberta Forest Conservation Strategy Steering Committee. 1997. Alberta forest conservation strategy. Alberta Environmental Protection, Edmonton, Alberta, Canada.

Alberta Resource Development. 2001. Annual report 2000/2001. Alberta Resource Development, Edmonton, Alberta, Canada.

Alberta Sustainable Resource Development. 2002. Historical wildfire database. Alberta Sustainable Resource Development, Edmonton, Alberta, Canada. Database available on line at: http://www3.gov.ab.ca/srd/index.html.

Benkman, C. 1993. Logging, conifers, and the conservation of crossbills. Conservation Biology 7:473-479.

Cumming, S. G. 1997. Landscape dynamics of the boreal mixedwood forest. Dissertation, University of British 
Columbia, Vancouver, British Columbia, Canada.

Donovan, T., F. Thompson, J. Faaborg, and J. Probst. 1995. Reproductive success of migratory birds in habitat sources and sinks. Conservation Biology 9:1380-1395.

Dyer, S. J., J. P. O'Neill, S. M. Wasel, and S. Boutin. 2001. Avoidance of industrial development by woodland caribou. Journal of Wildlife Management 65:531-542.

Dzus, E. 2001. Status of the woodland caribou (Rangifer tarandus caribou) in Alberta. Alberta Wildlife Status Report Number 30. Alberta Ministry of the Environment, Edmonton, Alberta, Canada.

Forestry Corporation. 2002. ALCES timber supply validation: comparison of ALCES and Woodstock/Stanley. Alberta Environmental Protection and Alberta Forest Products Association, Edmonton, Alberta, Canada.

Jones, J., F. Swanson, B. Wemple, and K. Snyder. 2000. Effects of roads on hydrology, geomorphology, and disturbance patches in stream networks. Conservation Biology 14:76-85.

Kennett, S. 2002. Integrated resource management in Alberta: past, present and benchmarks for the future. Canadian Institute of Resources Law, Calgary, Alberta, Canada.

Kirk, D., A. Diamond, K. Hobson, and A. Smith. 1996. Breeding bird communities of the western and northern Canadian boreal forest: relationship to forest type. Canadian Journal of Zoology 74:1749-1770.

Macnab, B., J. Daniels, and G. Laxer. 1999. Giving away the Alberta advantage: are Albertans receiving maximum revenues from their oil and gas? Parkland Institute, Edmonton, Alberta, Canada.

Murphy, P. 1985. Methods for evaluating the effects of forest fire management in Alberta. Dissertation, University of British Columbia, Vancouver, British Columbia, Canada.

Osko, T., and A. MacFarlane. 2001. Natural reforestation on seismic lines and wellsites in comparison to natural burns or logged sites. Alberta-Pacific Forest Industries, Boyle, Alberta, Canada.

Petroleum Communication Foundation. 2000. Canada's oil sands and heavy oil. Petroleum Communication Foundation, Calgary, Alberta, Canada.

Post, J. R., and M. Sullivan. 2002. Canada's recreational fisheries: the invisible collapse? Fisheries 27:6-17.

Revel, R. D., T. D. Dougherty, and D. J. Downing. 1984. Forest growth and regeneration along seismic lines. University of Calgary Press, Calgary, Alberta, Canada.

Trombulak, S., and C. Frissell. 2000. Review of ecological effects of roads on terrestrial and aquatic communities. Conservation Biology 14:18-30.

Walters, C., and C. Holling. 1990. Large-scale management experiments and learning by doing. Ecology 71:2060-2068.

Wetherell, D., and I. Kmet. 2000. Alberta's north: a history, 1890-1950. University of Alberta Press, Edmonton, Alberta, Canada. 